\title{
STRATEGI PROGRAMMING DALAM PENGEMASAN PROGRAM 'HAFIZ INDONESIA 2015” RCTI UNTUK MEMPEROLEH RATING SHARE TINGGI
}

\author{
Haronas Kutanto \\ Program Studi Ilmu Komunikasi \\ Fakultas Ilmu Komunikasi Universitas BudiLuhur \\ e-mail: haronas.kutanto@budiluhur.ac.id
}

\begin{abstract}
The aim of creation of the Hafiz program is to provide alternative displays for children. Hafiz Indonesia's television program features talented children in memorizing the Qur'an without any scenarios or scripts. So the participants present themselves on the television screen as it is. The purpose of this research is to know the Planning Programming strategy and Packaging Program of Hafiz Indonesia 2015 in RCTI, in order to get high share rating. This research method is using qualitative and descriptive. The theory used is Fred Wibowo's production concept. The results of programming strategy in production concept are (1) RCTI is stripping strategy on big audience and checker boarding strategy when the number of audience is decreasing, but RCTI also uses the strategy of tent poling to introduce new program. (2) The planning process of Hafiz Indonesia program is carried out in a mutual way, not only by the programming division, but starting from the analyst program. They are consisting of programming divisions and other people who are members of the program committee. (3) Preproduction activities will be aired and begun by casting ideas or ideas into an outline containing an event's program. The selected resource is the person who has the credibility and knows exactly about the topic to be discussed. Theoretically, the result of this research is expected to give a constrictive contribution to the development and assessment of communication science generally and practically, it is expected to be input for interested parties, either institution or company about "Hafiz Indonesia 2015" program and give a new color or inspiring to Indonesian children in this event program.
\end{abstract}

Keywords : Strategy Programming, Hafiz Indonesia, RCTI, Planning, Rating Share.

\begin{abstract}
ABSTRAK
Penciptaan Program Hafiz bertujuan untuk memberikan tayangan alternatif bagi anak - anak. Program televisi Hafiz Indonesia menampilkan anak - anak muda berbakat dalam menghafal Al-Quran tanpa ada skenario atau naskah. Jadi para peserta menampilkan dirinya di layar televisi dengan apa adanya. Tujuan Penelitian ini mengetahui secara mendalam Strategi Programing Pengemasan Program Acara Hafiz Indonesia 2015 di Rajawali Citra Televisi Indonesia guna memperoleh rating share tinggi. Metode penelitian ini dengan menggunakan kualitatif, Deskriptif teori yang di gunakan yaitu Konsep Produksi Fred Wibowo. Hasil Penelitiannya Strategi Programming Konsep Produksi yaitu : (1). RCTI yaitu strategi
\end{abstract}


stripping pada saat jumlah audiensbesar dan strategi checker boarding pada saat jumlah audiens mengalami penurunan, namun RCTI juga menggunakan strategi tentpolinguntuk memperkenalkan program barunya (2). Proses perencanaan program Hafiz Indonesia dilakukan secara bergotong royong tidak hanya oleh divisi programming saja, dimulai dari program analyst. Mereka terdiri dari divisi programming dan orang-orang lainnya yang tergabung dalam komite program. (3). Kegiatan pra produksi akan ditayangkan dan dimulai dengan penuangan ide atau gagasan ke dalam outline yang berisikan gambaran program suatu acara. Narasumber yang dipilih adalah orang yang memiliki kredibilitas dan mengetahui dengan pasti mengenai topik yang akan dibahas. Secara teoritis hasil penelitian ini diharapkan dapat memberikan kontribusi yang konstruktif bagi pengembangan dan pengkajian ilmu komunikasi umumnya dan secara praktis ini diharapkan dapat menjadi bahan masukan bagi pihak-pihak yang berkepentingan, baik lembaga atau perusahaan mengenai Program Acara "Hafiz Indonesia 2015" dan memberikan warna yang baru atau memberi inspirasi kepada anak-anak Indonesia dalam program acara.

\section{Kata Kunci : Strategi Programming, Hafiz Indonesia, Perencanaan, RCTI, Rating Share.}

\section{PENDAHULUAN}

Fenomena melalui ajang kompetisi menghafal Al-Quran Hafiz Indonesia pemirsa televisi dapat melihat kemampuan luar biasa dari anak-anak kecil Indonesia yang berjuang menjadi seorang Hafiz Indonesia muda. ${ }^{1}$ Program ini juga menarik perhatian publik hingga menjadikan Hafiz Indonesia sebagai Program Acara Ramadhan terbaik ajang KPI-MUI Award $2015^{2}$ dan Program Acara Ramadhan terfavorit di ajang Panasonic Gobel Awards 2015 . $^{3}$ Hafiz Indonesia adalah program islami dengan menandingkan anak-anak berusia 3-7 tahun yang hafal Qur'an. Program ini merupakan salah satu andalan RCTI di bulan Ramadhan. Persaingan program acara televisi yang sangat ketat antara stasiun televisi satu dengan stasiun televisi lainnya, membuat setiap program acaranya juga harus mempunyai kelebihan dan keunggulan untuk bisa mempertahankan pemirsa televisi agar tetap setia dan loyal pada suatu program acara, yang menarik bagi peneliti

\footnotetext{
${ }^{1}$ Hasil share TOP Performance RCTI, Update April 2015. Referensi RCTI TOP Program

${ }^{2}$ Di kutip dari “ Siaran Pers : Penghargaan Program Siaran Ramadhan 2015 ( www.KPI.GO.id ), terbit 31 Juli 2015. Di Akses 10 Januari 2016

${ }^{3}$ Program Rising Star Indonesia berhasil menggondol penghargaan Panasonic Gobel Awards 2015 di Jakarta, Kamis (28/5/2015). (Sindonews/Isra Triansyah)
} 
Program acara "Hafiz

Indonesia" menjadi program acara dan jarang atau bahkan satu-satunya reality showtalent search yang melombakan AlQur'an. Selain itu dalam acara ini peserta tidak di sertai dengan dukungan polling sms untuk penilaian peserta, tetapi hanya dewan jurilah yang mampu menilai, adapun yang menjadi penilaian di acara ini di antaranya adalah makhrajul huruf tajwid dan kelancaran para peserta dan program cara ini karena di kemas secara apik dan sederhana. ${ }^{4}$

Perkembangan media teknologi informasi khususnya televisi tentu saja membawa dampak positif dan dampak negatif serta perubahan yang dibawa dapat menyentuh segala aspek kehidupan masyarakat sehingga sangat luas jangkauan perubahan dalam komunikasi, seperti ungkapan tentang dampak televisi bagi dirinya.

Adanya televisi membuat saya semakin tahu akan perkembangan informasi yang ada atau situasi yang ada pada skala waktu tertentu, tapi terkadang juga televisi membuat saya khawatir dengan anak - anak saya karena Menghadirkan acara yang bukan sewajarnya ditonton oleh anak kecil, contohnya saja anak kecil sudah menonton berita yang menayangkan tentang realitas kejahatan ataupun yang lainya, dan itu memicu anak- anak untuk melakukannya. ${ }^{5}$

"Hafiz Indonesia" merupakan salah satu program acara di televisi yang mempunyai keunikan tersendiri dari program acara lainnya, selain melombakan anak - anak kecil yang berumur 3-7 tahun, seperti Adi salah satu peserta yang berumur 3 tahun yang pernah tampil para peserta juga harus memenuhi persyaratan mewajibkan menghafal minimal 30 juz dan di antaranya juga jus 29. Selain itu, Kelebihan "Hafiz Indonesia" ini memiliki sistem perlombaan lebih jelas dan gameslebih variatif, set dan grafis sudah lebih dinamis, konten peserta sangat kuat, bintang tamu internasional.

\footnotetext{
${ }^{4}$ Hafiz Indonesia 2015

${ }^{5}$ Hasil Wawancara, Yunisa Rahma Ibu Rumah Tangga. Januari 2016
} 
Dukungan terhadap televisi yang baik sangat penting untuk mengimbangi program yang bisa jadi merusak moral anak - anak kita. Acara "Hafiz Indonesia" Misalnya, kita bisa mendukung dengan cara menonton acara tersebut, memberi atensi, dan testimoni positif mengenai acara tersebut, dan secara masif menggalangdukungan untuk keberlangsungan acara tersebut baik via social media ataupun lainnya

"Hafiz Indonesia" merupakan program islami dengan melombakan anak - anak berusia 3-7 tahun yang hafal Al-Qur'an, ini merupakan program andalan RCTI di bulan Ramadhan. Program acara "Hafiz Indonesia" acaranya dimulai semenjak awal ramadan, dan disiarkan setiap sore pukul 14.30 WIB. Hafiz Indonesia formasi awal di pandu oleh Irfan Hakim sebagai Presenter atau presenter dan beberapa juri yang sudah ahli dibidangnnya, seperti Ust. Riza, K. Lulu dan Ust. Caem Maulana dan juga Alvin Firmansyah (10 tahun) Hafiz Indonesia cilik hafal 17 juz. ${ }^{6}$

Dalam mengasilkan penilaian positif dari masyarakat terhadap program acara televisi tidaklah lepas dari sebuah perencanaan dan pengemasan program yang terkonsep melalui proses kreatifitas yang nantinya akan mempengaruhi rating yang di hasilkan serta penilaian program yang berkualitas di benak penonton yang menikmatinya. Strategi program televisi di perlukan agar setiap program yang di tayangkan mencapai hasil yang optimal atau perencanaan konsep yang matang oleh seluruh tim produksi (Produser) dalam mengasilkan pengemasan program yang berkualitas, mendidik dan menghibur. Mendapatkan data rating penonton yang bagus, serta kepuasaan dalam menghadirkan sebuah tayangan yang dinikmati banyak audiens atau masyarakat.

Penelitian ini merumuskan permasalahan tentang bagaimana Strategi Programming, Perencanaan serta pengemasan program Acara "Hafiz Indonesia 2015" dengan tujuan Strategi Programing Perencanaan dan Pengemasan Program Acara Hafiz Indonesia 2015 di Rajawali Citra Televisi Indonesia untuk memperoleh Rating Share Tinggi”

${ }^{6}$ Program Acara Hafiz Indonesia 2014 


\section{KERANGKA PEMIKIRA Konsep Programming}

Program merupakan ujung tombak sebuah stasiun televisi yang langsung bersentuhan dengan pemirsa, karena itulah diperlukan pengaturan program yang tepat Programing dapat didefinisikan sebagai strategi penggunaan program yang sudah tersusun yang dirancang untuk menarik audiensce yang telah ditentukan.Programing can be defined as the strategic use of programs arranged in schedules designed to attract carefully defined target audiensces. ${ }^{10}$

Programing yang bagus menjadi
sebuah landasan dasar dalam
memenangkan persaingan. Dengan
didukung oleh strategi yang meliputi

perencanaan (planning) dan pengarahan (directing) terhadap segala kegiatan operasional seperti pengaturan jaringan siaran dan penyusunan programprogram acara yang sedemikian rupa sehingga tepat sasaran kepada target audiensce yang tetap ditetapkan. Hal ini sangat penting sifatnya mengingat perkembangan televisi lokal di daerahsemakin banyak di tengah maraknya stasiun televisi nasional menayangkan tayangan program acara yang seragam.

\section{Konsep Produksi}

Suatu program dihasilkan melalui proses produksi yang memerlukan banyak peralatan, dana, dan tenaga dari berbagai profesi kreatif. Proses produksi itu sendiri terdiri atas tiga bagian utama; yaitu ${ }^{11}$

\footnotetext{
${ }^{10}$ J.K Eastment dkk. 1999. Status Comsuption in Consumer Behavior Scale Development and Validation. Journal Of Marketing Theory and Practise.

11 Morissan, Manajemen Media Penyiaran, Strategi Mengelola Radio Dan Televisi 2009 : 270-27
} 
1. Tahap Pra Produksi atau Perencanaan

Kegiatan mulai dari pembahasan ide (brainstorming) dan memproses materi outline pengemasan program seperti tampilan panggung (stage floor), tata cahaya (light treatment), tata letak kamera (blocking camera) target audiens, budgeting, episode, durasi, dan segmen. Proses ini adalah proses interaksi antara kreativitas manusia dengan peralatan pendukung yang perlukan untuk kebutuhan produksi program televisi. Baik buruknya proses produksi akan sangat ditentukan oleh perencanaan tim produksi. Perencanaan tersebut merupakan proses kreatif yang dituangkan dalam skrip (rundown produksi) yang nantinya akan dieksekusi dalam proses produksi.

2. Tahap Produksi

Setelah melewati proses pra-produksi yang menghasilkan outline produksi seperti rundown script. Rundown script itulah yang akan dijadikan acuan eksekusi produksi (Shooting) program Hafiz Indonesia. Dalam produksi program tersebutdibagi menjadi dua tim produksi, yaitu tim produksi indoor (distudio) dan tim produksi outdoor (diluar studio). Proses rekaman (tapping) program dilakukan sebulan sebelum tanggal penayangan dengan format (live on tape). Saat proses produksi perlu dilakukan pemeriksaan ulang (playback) review per-segmen, apakah ada kesalahan atau tidak dalam proses perekaman, bila ada kesalahan teknis atau kesalahan pengisi acara maka perlu di re-take atau syuting ulang pada segmen tersebut, sampai mendapatkan master visual dan audio yang aman.

3. Tahap Pasca Produksi

Setelah proses produksi pengambilan gambarselesai dan dinyatakan aman, master atau materi video tersebut masuk pada tahap editing, dalam hal ini penyuntingan gambar atau pengemasan akhir, hingga dinyatakan siap untuk ditayangkan per-episode. Tentunya materi video yang akan ditayangkan telah dievaluasi (playback) dan dinyatakan aman oleh produser program acara tersebut. 
Strategi

Strategi pada hakekatnya adalah

perencanaan

(management) untuk mencapai suatu tujuan.Akan tetapi untuk mencapai tujuan tersebut strategi tidak berfungsi sebagai peta jalan yang hanya menunjukan arah saja, melainkan harus mampu menunjukan bagaimana taktik operasionalnya.

\section{Sedangkan menurut Jauch \\ dan Glueck (1998:6)strategi \\ adalah rencana yang disatukan menyeluruh secara terpadu yang mengkaitkan keunggulan strategi yang dimiliki oleh masing-masing perusahaan serta tantangan lingkungan dan dirancang untuk memastikan bahwa tujuan serta misi perusahaan dapat tercapai melalui pelaksanaan yang tepat oleh perusahaan. Suwarsono} (2008:6) juga mengemukakan pendapatnya tentang strategi, yaitu usaha managerial untuk menumbuhkembangkan kekuatan perusahaan dalam mengeksploitasi peluang bisnis yang muncul guna mencapai tujuan perusahaan yang telah ditetapkan sesuai dengan misi yang telah ditentukan strategi mencerminkan kesadaran organisasi atau perusahaan mengenai bagaimana, kapan, dan dimana organisasiatau perusahaan harus bersaing dan organisasi atau perusahaan apa yang menjadipesaingnya.

Pengemasan, Program, Segment Pembaharuan kemasan konsep di media televisi mengacu pada Al- Qur'an dapat di identifikasi sebagai panggilan iman pencerahan Agama, dan proses masyarakat menuju kualitas terutama mendidik dari sekarang untuk karakter anak bangsa dalam upaya membenahi moral mereka sebagai generasi penerus. Sebagai aktualisasi iman merupakan keharusan, dan menjadi tugas penting dan suci bagi setiap muslim, setingkat dengan kapasitas dan kapabilitas yang di miliki masing -masing.

Dakwah yang di lakukan oleh anak - anak merupakan modal untuk menjadi individu maupun kolektif melalui organisasi perlu mempertimbangkan dan memperhatikan keperluan dan kepentingan masyarakat yang menjadi objek atau sasarannya. 
Perluasan dan penguatan jaringan atau kerja sama dengan lembaga lembaga yang bergerak di bidang dakwah, dengan paradigma baru yang menekankan pembaharuan dalam perluasan serta kerjasama dengan lembaga - lembaga lainnya. Penguatan dana primer serta sekunder untuk mendanai program acara ini karena ruh dari penayangan kemasan dakwah di televisi adalah wajib ada dana yang cukup besar. Hal ini mengacu pada ideologi industri media massaadalah profit yang tinggi, yang di peroleh melalui produk atau acara yang memiliki nilai jual tinggi, bahasa teknisnya adalah menyesuaikan dengan motivasikhalayak.

\section{Televisi}

Kata televisi terdiri dari kata tele yang berarti jarak dalam bahasa Yunani dan kata visi yang berarti citra atau gambar dalam bahasa latin. Jadi, kata televisi berarti suatu sistem penyajian gambar berikut suara dari suatu tempat yang berjarak jauh ${ }^{12}$. Pendapat lain menyebutkan, televisi dalam

bahasa Inggris disebut television. Televisi berasal dari kata tele (bahasa yunani) dan vision (bahasa latin); yang mempunyai arti masing-masing jauh (tele) dan melihat (vision).Jadi televisi berarti melihat dengan jauh ${ }^{13}$.

Televisi merupakan salah satu bentuk media massa sebagai alat komunikasi massa. Komunikasi massa adalah pesan yang dikomunikasikan melalui media massa pada sejumlah besar orang. menjelaskan bahwa, media televisi memiliki fungsi yang lebih dominan pada hiburan dibandingkan dengan fungsi memberikan informasi dan mendidik.

\footnotetext{
${ }^{12}$ Sutisno. P.C.S., Pedoman Praktis Penulisan Skenario Televisi dan Radio (Jakarta: PT Grasindo, 1993), h. 1

${ }^{13}$ Sunarjo Djoenaesih S, Himpunan Istilah Komunikasi, cet ke-2. (Yogyakarta: Liberty, 1983),h. 125.
} 
METODE PENELITIAN

\begin{abstract}
Peneliti menggunakan pendekatan paradigma Post Positivisme karena peneliti tidak memaknai perilaku subyek ataupun objek dengan alasan peneliti ingin meneliti secara sistematis tentang Strategi Programing Perencanaan, pengemasan dan proses produksi pada program acara Hafiz Indonesia 2015, dalam Program Hafiz Indonesia RCTI di Jakarta yang berarti paradigma ini tidak mendasarkan penelitian kuantitatif yang menggunakan informan dan data yang berupa angka, karena adanya konsep
\end{abstract}

penggeneralisasian, paradigma post - positivisme aliran ini menegaskan arti penting dari hubungan interaksi antara peneliti dengan objek yang bersifat netral agar tingkat subyektifitas dapat di kurangi, karena peneliti menitikberatkan pada observasi di RCTI khusunya program yang di teliti, wawancara kepada penanggung jawab dan program acara yang bertugas

Islam , nah di sini anak - anak selain belajar banyak manfaat yang mereka dapatkan lewat mengenai Hafiz Indonesia 2015, dan dokumentasi tersebut berupa tulisantulisan berbentuk catatan, buku, naskah, dokumen ataupun arsip -arsip yang terkait dengan pembahasan penelitian ini. Penelitian mengambil Lokasi di Studio 01 (Komplek RCTI Kebon Jeruk), Jalan Raya Perjuangan No.1 Kebon Jeruk, Jakarta Barat.

\section{HASIL PENELITIAN DAN PEMBAHASAN}

Strategi Program acara "Hafiz Indonesia" acaranya dimulai semenjak awal ramadan juli 2015 dan disiarkan setiap sore pukul 14.30 - 15.00 WIB. Acara ini banyak mendapat animo masyarakat yang positif seperti yang di ungkapan oleh produser Hafiz Indonesia:

" Berawal dari khayalan acara ini, menjadi sebuah kenyataan karena acara yang biasa saya buat hanya hari biasa tidak seperti saat ini di hari raya besar, dan itu merupakan godaan bahkan hal yang pantas dan positif sesuai tema hari Raya keagamaan, semoga ini menjadi modal positif bagi anak - anak Indonesia “. ${ }^{14}$ 


\section{Tabel 4.1}

\section{Hafis Vs Competitor 1}

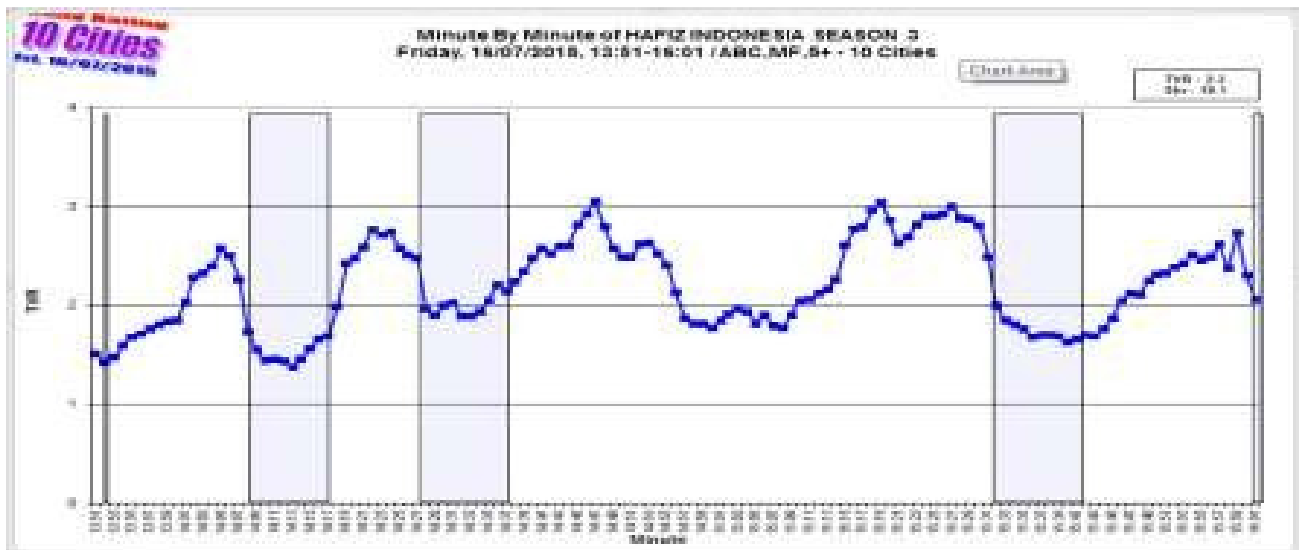

Hal itu merupakan kesuksesan dimana RCTI menggunakan strategi para produser bersama rekan atau struktur kerabat kerja Hafiz Indonesia stripping yaitu strategi untuk menjaga 2015. Keberhasilan tersebut tidak jauh jumlah audiens dengan menempatkan beda dari strategi yang dia gunakan, program yang sama pada slot waktu yang sama selama hari berturut-turut.

Tabel 4.2

\section{Hafis Vs Competitor 2}

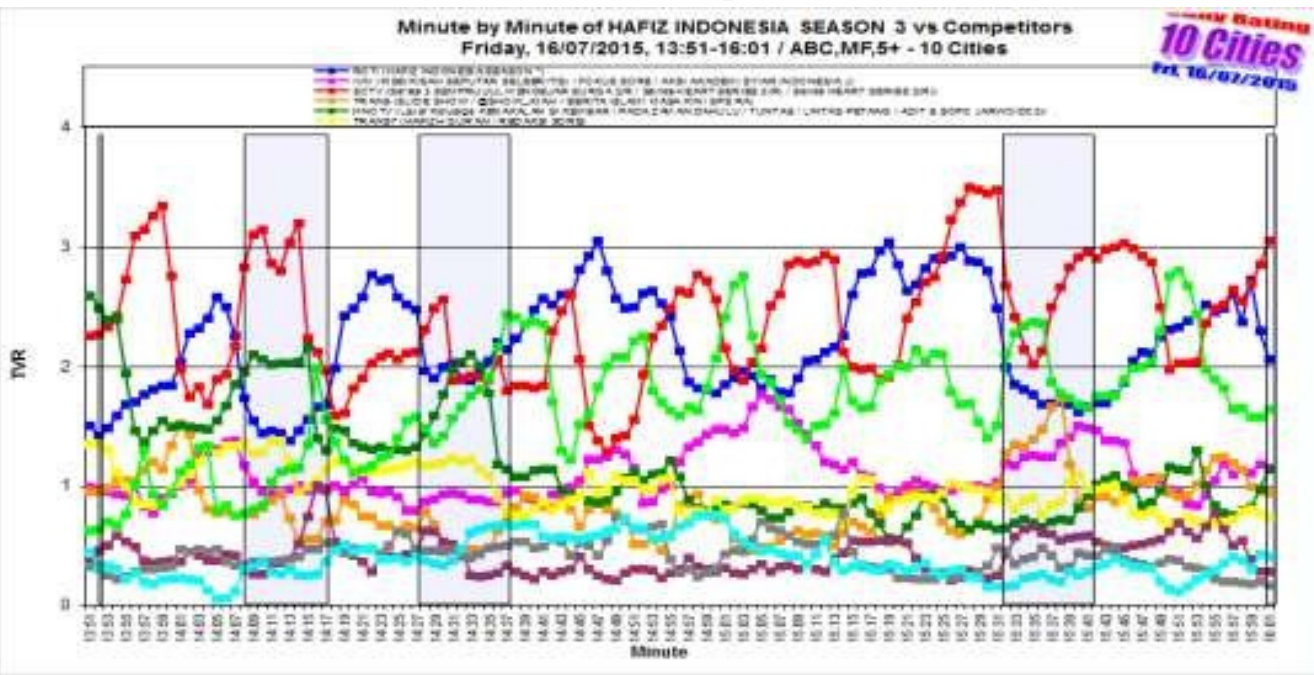

\footnotetext{
${ }^{14}$ Hasil Wawancara dengan Erwin Amirul, Produser Hafiz Indonesia 2015. Januari 2015
} 
Tabel 4.3

Audience Class Juni - Juli

2015

\begin{tabular}{|l|l|l|l|l|l|l|l|}
\hline & Senin & Selasa & Rabu & Kamis & Jumat & Sabtu & Minggu \\
\hline 04.00 & $\begin{array}{l}\text { Liga } \\
\text { BBVA }\end{array}$ & $\begin{array}{l}\text { Asw. } \\
\text { Ustad }\end{array}$ & $\begin{array}{l}\text { Asw. } \\
\text { Ustad }\end{array}$ & $\begin{array}{l}\text { Asw. } \\
\text { Ustad }\end{array}$ & $\begin{array}{l}\text { Asw. } \\
\text { Ustad }\end{array}$ & $\begin{array}{l}\text { Asw. } \\
\text { Ustad }\end{array}$ & $\begin{array}{l}\text { Asw. } \\
\text { Ustad }\end{array}$ \\
\hline 06.00 & Go Spot & Go Spot & Go Spot & Go Spot & Go Spot & Go Spot & Go Spot \\
\hline O7.30 & Dashyat & Dashyat & Dashyat & Dashyat & Dashyat & Dashyat & Dashyat \\
\hline 10.30 & Intens & Intens & Intens & Intens & Intens & Intens & Intens \\
\hline 11.00 & Silet & Silet & Silet & Silet & Silet & Silet & Silet \\
\hline 12.00 & Sp.Siang & Sp.Siang & Sp.Siang & Sp.Siang & Sp.Siang & Sp.Siang & Sp.Siang \\
\hline 13.50 & $\begin{array}{l}\text { Hafiz } \\
\text { Indonesia }\end{array}$ & $\begin{array}{l}\text { Hafiz } \\
\text { Indonesia }\end{array}$ & $\begin{array}{l}\text { Hafiz } \\
\text { Indonesia }\end{array}$ & $\begin{array}{l}\text { Hafiz } \\
\text { Indonesia }\end{array}$ & $\begin{array}{l}\text { Hafiz } \\
\text { Indonesia }\end{array}$ & $\begin{array}{l}\text { Hafiz } \\
\text { Indonesia }\end{array}$ & $\begin{array}{l}\text { Hafiz } \\
\text { Indonesia }\end{array}$ \\
\hline 18.00 & $\begin{array}{l}\text { Anak } \\
\text { Manusia }\end{array}$ & $\begin{array}{l}\text { Anak } \\
\text { Manusia }\end{array}$ & $\begin{array}{l}\text { Anak } \\
\text { Manusia }\end{array}$ & $\begin{array}{l}\text { Anak } \\
\text { Manusia }\end{array}$ & $\begin{array}{l}\text { Anak } \\
\text { Manusia }\end{array}$ & $\begin{array}{l}\text { Anak } \\
\text { Manusia }\end{array}$ & $\begin{array}{l}\text { Anak } \\
\text { Manusia }\end{array}$ \\
\hline $\begin{array}{l}\text { Tukang } \\
\text { Bubur naik } \\
\text { Haji }\end{array}$ & $\begin{array}{l}\text { Tukang } \\
\text { Bubur naik } \\
\text { Haji }\end{array}$ & $\begin{array}{l}\text { Tukang } \\
\text { Bubur naik } \\
\text { Haji }\end{array}$ & $\begin{array}{l}\text { Tukang } \\
\text { Bubur naik } \\
\text { Haji }\end{array}$ & $\begin{array}{l}\text { Tukang } \\
\text { Bubur naik } \\
\text { Haji }\end{array}$ & $\begin{array}{l}\text { Tukang } \\
\text { Bubur naik } \\
\text { Haji }\end{array}$ & $\begin{array}{l}\text { Tukang } \\
\text { Bubur naik } \\
\text { Haji }\end{array}$ \\
\hline
\end{tabular}

1 Dapat dilihat pada waktu Early Morning pukul 02.00 WIB -04.59 WIB ( audiens Kelas A-B, jumlah audiens sedikit) terdapat Program AssalamualaikumUstad.

2. Lalu waktu Morning Time yaitu pukul 05.00 08.59 WIB pada hari senin- jumat (audiens Kelas A-B, semua umur atau jumlah audiens banyak).

3. RCTI menayangkan Go Spot pada pukul 06.00 WIB, Dahsyat pada pukul 07.00 WIB.

4. Kemudian pada waktu Day Time yaitu pukul 09.00 WIB - 11.59 WIB (audiens kelas C,D,E, anakanak, perempuan, semua umur atau jumlah audiens sedikit) RCTI meletakkan INTENS pada pukul
10.30, dilanjutkan dengan SILET pada pukul 11.00WIB.

5. Selanjutnya pada waktu Noon Time pukul 12.00 WIB -15.59 WIB hari senin- minggu (audiens kelas C,D,E, anak -anak, perempuan, semua umur.jumlah audiens sedikit) terdapat acara Seputar Indonesia Siang pada pukul 12.00 WIB, selanjutnya program Buka- Bukaan pada pukul 12.30 WIB.

6. Sedangkan pada waktu Early Prime Time 18.00 WIB -18.59 WIB dan Central Prime Time (audiens kelas A, B, C, D, E, semua audiens atau jumlahnya besar) RCTI menayangkan program drama sinetron padapukul 
7. 20.00 hingga waktu Late Prime

Time 21.00 WIB - 22.29 WIB

(audiens kelas A, B, C, D, E, semua audiens atau jumlah audiens besar)

8. Strategi lainnya yang digunakan oleh RCTI adalah tentpoling yaitu langkah perencanaan slot waktu bagi program acara yang baru, sebelum dan setelah program ungulan yang mempunyai audienscukup besar dengan menayangkan Fortune Cookies dan East Java Tournament 2013 pada pukul

9. $\quad 17.00$ yang masuk waktu Evening Time 16.00 WIB - 17.59 WIB (audiens kelas A, B, C, D, E, anakanak, perempuan, semua umur atau audiens mulai besar) sebelum penayangan program unggulan pada waktu Prime Time

Tabel 4.4

Tenpolling

Tayangan Prime Time

\begin{tabular}{|l|l|l|l|l|l|l|l|}
\hline & Senin & Selasa & Rabu & Kamis & Jumat & Sabtu & Minggu \\
\hline $17.00 \mathrm{Wib}$ & Fortunecookie & - & - & - & - & - & - \\
\hline $18.00 \mathrm{Wib}$ & $\begin{array}{l}\text { Anak-anak } \\
\text { Manusia }\end{array}$ & - & - & - & - & - & - \\
\hline $20.00 \mathrm{Wib}$ & $\begin{array}{l}\text { Tukang bubur } \\
\text { naik haji }\end{array}$ & - & - & - & - & - & - \\
\hline
\end{tabular}

Prime Time

Untuk tayangan yang tayang setelah waktu prime time, RCTI menggunakan strategi checkerboarding yaitu strategi untuk meraih jumlah audiens dengan menempatkan program yang berbeda pada slot waktu yang sama setiap harinya. Pada waktu night time22.30 WIB -23.59 WIB (audiens kelas A,B, laki-laki jumlah audiens mulai menurun) diisi dengan tayangan berformat Film Box Office.

\section{Pra-Produksi (Perencanaan)}

Materi sangat penting untuk menentukan program acara yang akan di buat, tanpa ada materi, program tidak akan terlaksana dengan baik seperti ungkapan Produser Hafiz Indonesia $^{15}$

Perjuangan seorang produser yang di sampaikan di atas, tentu tidak mudah karena mencentuskan ide itu memang mudah, tetapi harus memperhatikan point - point yang di 
anggap bagian dari ide yang di cetuskan.Ketika referensi yang di berikan oleh pihak programing dan key word nya itu merupakan hantaran untuk membuat sebuah program yang menarik yang bertemakan anak - anak kecil islami. Awal mulanya ketika konsep itu terbentuk, banyak revisi yang dihadapi oleh seorang produser terutama pada segmentasi yang kurang jelas, tidak sesuai dengan keinginan programing, dan sempat bingung dengan keinginan programing.

\section{$\underline{\text { Treatment }}$}

- OpeningAct : Qori

- $\quad$ VT Pretitle28

- Present ke-28 besarfinalis

- Present Juri

- 28 peserta dibagi menjadi 2 kelompok (@14orang)

- Adapun nama-nama timnya adalah sbb: Zaid bin Tsabit, Ubay bin Ka'ab

- Estafet surat perkelompok

- Chit chat dan eksplor bakat individu perkelompok.

\section{AUDISI HAFIZ INDONESIA 2015}

Assalamu'allaikum Bunda, Ayanda dan sahabat-sahabat semua Alhamdulillah, Semoga sehat wal'afiat selalu. InsyaAllah Hafiz Indonesia Indonesia 2014 siap dilaksanakan kembali.

Hafiz Indonesia RCTI Program inspiratif yang menghadirkan anak- anak berbakat yg mampu menghafal sebagian atau seluruh Al-Quran. Program yang dapat menumbuhkan minat baca Al-Quran ini

InsyaAllah akan membuka pendaftaran "Hafiz Indonesia 2015".

Syarat: Anak usia 3 s/d 7 tahun minimal menghafal 1 juz (pada juz ke 30) dengan tajwid dan tartil yang indah. Pendaftaran ditutup tgl 10 Maret 2015.Silahkan mendownload folmulir di http://bit.ly/1b81X6o\& mengirimkan formulir, foto \& video ke TIM HAFIZ INDONESIA RCTI via pos.

Jl. Raya Pejuangan no. 1 Gd.Anex-RCTI Kebon Jeruk, Jakarta Barat.

Bunda, Ayanda dan sahabat-sahabat semua... Yuk, ikut sertakan anak-anak, murid-murid dan saudara-saudara kita dlm program acara Hafiz Indonesia, karenanya buruan kirim data diri ke tim Hafiz Indonesia 2015.

Terimakasih, Salam Fastabiqul Khoirot Semangat dan selalu ceria

\section{Gambar 4.1}

\section{Tagline Audisi Hafiz Indonesia 2014}

\footnotetext{
${ }^{15}$ Wawancara dengan Erwin Amirul, Produser Hafiz Indonesia RCTI, November 2015
} 
Tagline yang tertulis dalam auidisi itu, para masyarakat Indonesia yang merasa bahwa anaknya memiliki kemampuan untuk mengahafal tentu saja berusaha untu mendaftarkan anak - anaknya, apa lagi acara ini sangat mengedukasi bagi anak - anak Indonesia, setidaknya kurang permainan game yang dia lakukan setiap hari, ini merupakan modal untruk para ibu - ibu agar memberikan untuk mengambil peluang yang diberikan oleh RCTI.

Outline dalam sebuah acara sangat penting agar acara yang di susun atau direncanakan dapat terlaksana sesuai dengan jadwal yang akan di tayangkan. Di bawah ini merupakan outline dari perencanaan Program Hafiz Indonesia yang merupakan bagian program acara bertahap.

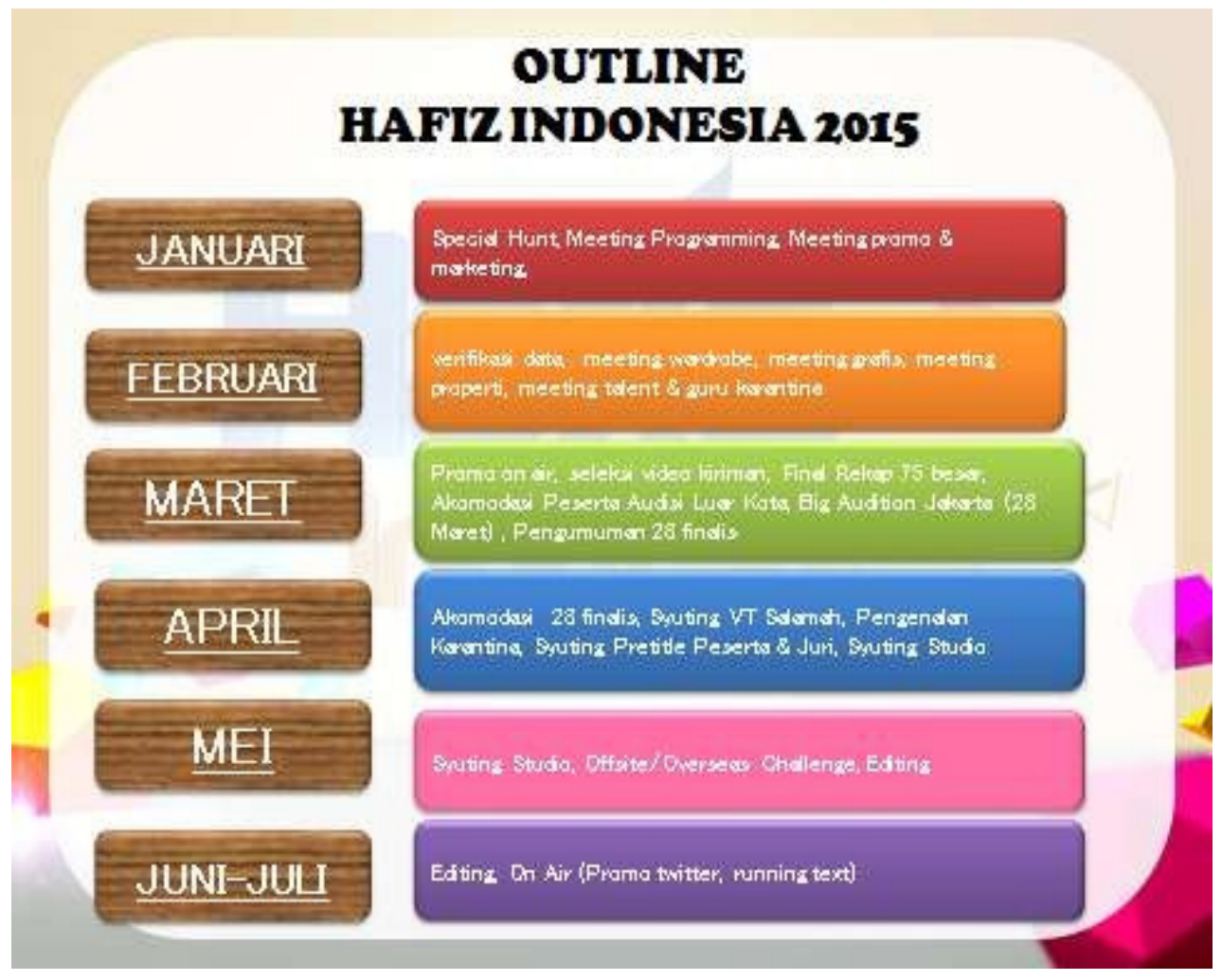

Gambar 4.2

Outline Hafiz Indonesia 
Memanfaatkan

momen

tahunan ini, biasanya stasiun televisi swasta maupun pemerintah sibuk mengharapberkah. Sayangnya, berkah yang awalnya bermakna ziyaadatul khair (bertambahnya kebaikan) banyak mengalami penyempitan
makna.Bahkan implementasi di lapangan sudah tidak jarang melenceng dari makna "kebaikan" yang hakiki.Kita ambil contoh, program sahur di beberapa stasiun televisi.

\section{TARAPAN BAFIZ INDONESLA 20IS}

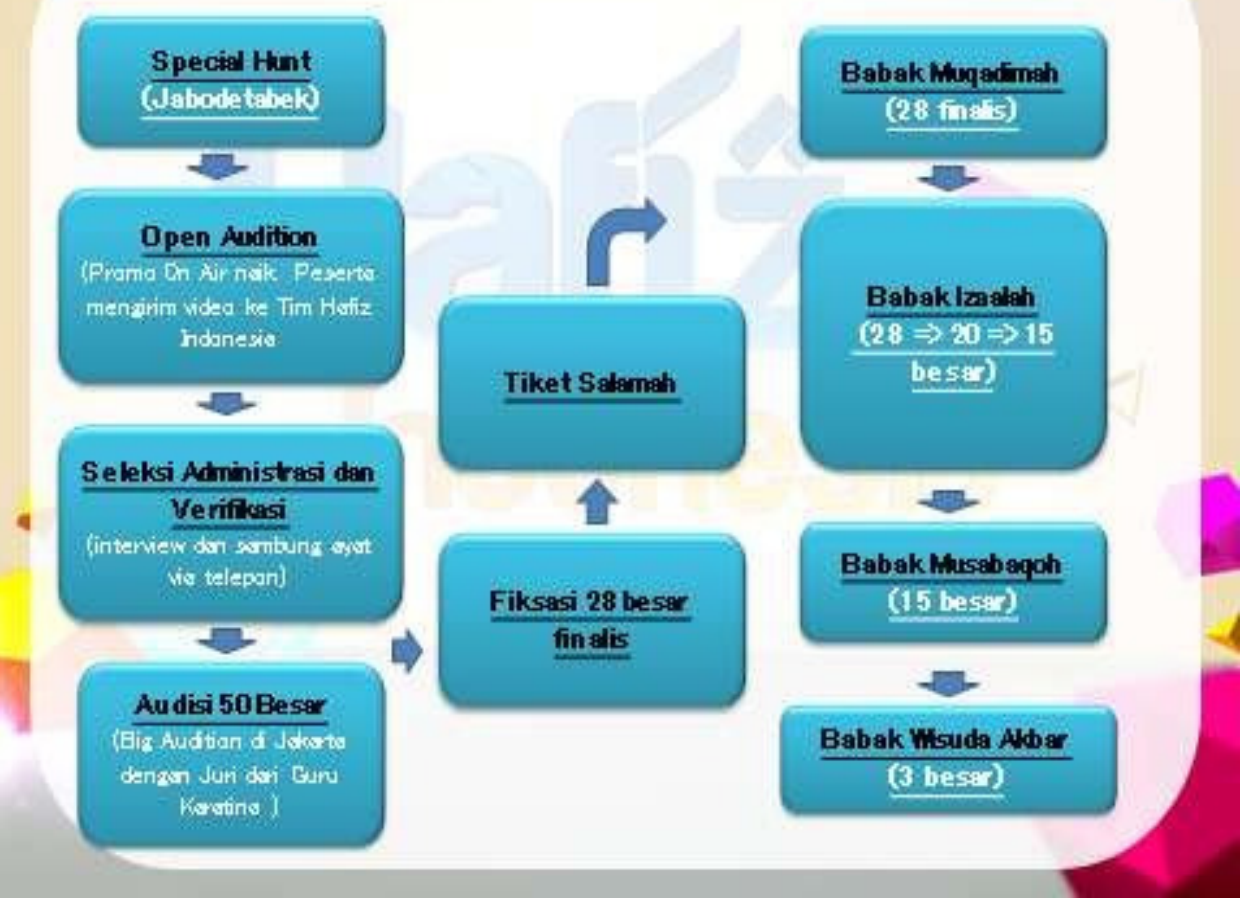

Gambar 4.3

Konsep Acara Hafiz Indonesia 


\section{Presenter}

Presenter secara umum diartikan sebagai orang yang memegang acara suatu tertentu. KeberadaanPresenter biasanya identik dengan acara yang di bawakannya. Dengan demikian, selain jenis acara figur Presenter yang bersangkutan akan memegang peranan penting dan kehadiran seorang Presenter yang berkarakter akan menjadi daya tarik suatu acara .pertimbangan dan pemilihan Presenter tidak hanya berdasarkan karena kecantikannya atau popularitasnya tetapi intergritas dan karakternya.

Produksi (eksekusi program outdoor atau indoor) kegiatan produksi antara lain;

\section{Reharsal Studio}

Jika semua persiapan sudah dijalankandengan baik saat pra produksi, sebetulnya saat produksi bukan hal yang sulit. Set baik studio atau non studio harus sudah siap untuk digunakan shooting. Rehearsal atau latihan sebaiknya dilakukan di lokasi shooting, hal ini untuk memudahkan koreksi jika ada perubahan atau apapun kebutuhan produksi tersebut.

\section{Rehearsal Crew}

Setidaknya ada dua cara bagaimana produser menggunakan sumber daya manusia atau crew yang akan dilibatkan dalam produksi acara televisi. Pertama dengan membangun crew, yakni benar-benar menentukan crew siapa saja yang akan dilibatkan. Kedua dengan menyusun crew, lantas meminta sumber daya tersebut pada department support. Yang paling banyak dilakukan adalah dengan cara kedua, karena hampir semua stasiun televisi mmeiliki departemen support yang akan mensuplai crew yang dibutuhkan dalam kegiatan produksi.

\section{Shooting}

Paska produksi merupakan gerbang terakhir dari pembuatan acara televisi.Materi hasil shooting diberikan pada departemen paska produksi.Sebelumnya, produser memberikan arahan pada chief editor tentang konsep acara yang dibuat.Menyunting gambar bukan sekadar memotong dan menyambung gambar. Lebih dari itu editor baiknya punya rasa seni juga, sehingga hasil yang akan ditayangkan bukan sambungan atau potongan mekanis saja. Editor merupakan story teller, ia harus mampu bertutur dengan bahasa gambar.

\section{Tahap Pengemasan}

Sebanyak 32 anak hebat dari seluruh Indonesia akan beradu kemampuan dalam menghafalkan dan melafalkan ayat-ayat suci dan melewati 5 tahap, yaitu tahap salamah (audisi), tahap muqadimah (perkenalan), tahap Izaalah (eliminasi), tahap Musabaqah 
(perlombaan) dan babak terakhir, Wisuda Akbar. Dibawakan oleh Irfan Hakim dan empat juri; Syeikh Ali Jaber, Prof. Dr. Nasaruddin Umar, Prof. Dr. Amir Faishol Fath dan Ustadzah Lulu Susanti.

\section{Pembahasan, Segmentasi, Ploting} Strategi Programing yang terjadi di RCTI, di mana sangat mempengaruhi Program Acara Hafiz Indonesia. Terlihat dari program yang ditayangkan pada waktu Morning Time 05.00 WIB - 08.59 WIB (audiens Kelas A-B, semua umur atau jumlah audiens banyak) dengan perkiraan banyak audiens anak-anak yang menonton maka dimulai dari pukul 06.00 hingga 08.30 RCTI mengisinya dengan tayangan khusus liburan berformat kartun dan fantasi. Strategi lainnya yang digunakan oleh RCTI adalah Tentpoling yaitu langkah perencanaan slot waktu bagi program acara yang baru, sebelum dan setelah program ungulan yang mempunyai audienscukup besar seperti program acara "Hafiz Indonesia”.

$$
\text { Proses perencanaan program }
$$

Hafiz Indonesia RCTI dilakukan secara bergotong royong tidak hanya oleh divisi programing saja, dimulai dari program analyst. Mereka terdiri dari divisi programing dan orang-orang lainnya yang tergabung dalam komite program.
Program analyst memberikan ide dan garis-garis besar mengenai program Acara Hafiz Indonesia apa yang sebaiknya dibuat. Setelah itu, disampaikanlah kepada program maker untuk merencanakan program seperti apakah yang akan dibuat, konsep, tujuan serta temanya." Perencanaan program juga terkait dengan kemampuan teknik dan administrasi yang harus mampu mendukung kelancaran proses produksi dan siaran, karena output organisasi penyiaran adalah siaran program acara.

Berkaitan dengan tahap pra produksi Erwin sebagai informan pertama, menjelaskan bahwa: "Pada tahap ini produser akan mengemukakan perkiraan susunan acara yang bersifat fleksibel dan dapat berubah tergantung perkembangan acara pada saat berlangsungnya program, namun tidak keluar dari konsep awal yang telah disepakati. Pada tahap ini terjadi interaksi antara kreativitas dan peralatan pendukung yang tersedia.

Sebelum memulai tahap produksi, produser program memimpin rapat dengan seluruh crew untuk membahas susunan acara (rundown).Erwin Selaku informan pertama menjelaskan mengenai tahapan produksi. Pada tahap produksi koordinasi antara produser dengan floor director 
berlangsung selama berjalannya proses

produksi untuk mengkoordinasikan dengan semua kerabat yang bertugas. Floor director merupakan pimpinan di studio, di beberapa stasiun televisi, floor director biasa disebut sebagai floor manager.Floor director adalah kepanjangan tangan dari Program Director atau $P D$.

Secara umum tahap paska produksi ini dikenal dengan tahap editing video, meski pada kenyataannya banyak unsur pekerjaan lain yang terlibat, misalnya pembuatan animasi dan visual efek, sound engineering danimageediting. Keseluruhan tahap ini untuk memaksimalkan hasil gambar. Erwin sebagai informan pertama menjelaskan mengenai tahap paska produksi Program Hafiz Indonesia yaitu pada tahap ini, produser memiliki tanggungjawab untuk memilih editor sebagai penanggungjawab pada saat melakukan tahap editing.

Evaluasi program merupakan bentuk kegiatan terakhir programing. Pada tahap ini, programmer harus mampu membaca situasi dan melihat performa program.Hal ini bertujuan untuk terus menarik dan mempertahankan jumlah pemirsa sebanyak mungkin. Dalam evaluasi program Acara Hafiz Indonesia Ini ini juga dilihat sejauh mana program- program yang ditampilkan mampu mencapai tujuan yang ditetapkan

\section{SIMPULAN}

Setelah melihat strategi yang digunakan oleh RCTI yaitu strategi stripping pada saat jumlah audiens besar dan strategi checkerboardingpada saat jumlah audiens mengalami penurunan, namun RCTI juga menggunakan strategi tentpolinguntuk memperkenalkan program barunya

$$
\text { Penciptaan program Hafiz }
$$

Indonesia bertujuan untuk memberikan tayangan alternatif bagi anak - anak. Program televisi Hafiz Indonesia menampilkan anak - anak muda berbakat dalam menghafal Al-Quran tanpa ada skenario atau naskah. Jadi para peserta menampilkan dirinya di layar televisi dengan apa adanya. Ini memberikan inspirasi kepada teman sebayanya untuk menghafalkan Al-Quran. Adapun perencanaan dan pengemasan acara program Hafiz Indonesia pada yaitu :

1. Proses perencanaan program Hafiz Indonesia 2014, RCTI di Jakarta dilakukan secara bergotong royong tidak hanya oleh divisi programing saja, dimulai dari program analyst. Mereka terdiri dari divisi programing dan orang-orang 
lainnya yang tergabung dalam komite program.

2. Kegiatan pra produksi akan ditayangkan dan dimulai dengan penuangan ide atau gagasan ke dalam outline yang berisikan gambaran program suatu acara. Narasumber yang dipilih adalah orang yang memiliki kredibilitas dan mengetahui dengan pasti mengenai topik yang akan dibahas.

3. Pengemasan program yang dilakukan editor harus selalu berbeda, artinya di setiap episode ada sebuah hal yang menarik yang membuat penonton ingin terus menyaksikan program ini, mungkin itu dari caraeditor menyambung gambar demi gambar, pemilihan warna dan pengaturan suara.

Dalam hal ini proses
komunikasi organisasi yang
terjadi di acara Hafiz Indonesia
adalah atasan dan bawahan,
mereka saling memahan satu
sama lain kebutuhan yang
dilakukan setiap acara, saling
membantu apabila masing -

masing jobdeskmereka telah terselesaikan dan membutuhkan bantuan, sehingga kerja sama sebagai modal kunci keberhasilan dalam organisasi Struktur Kerabat Kerja Hafiz Indonesia.

\section{Saran}

1. Program Hafiz Indonesia semoga dapat terus diproduksi setiap tahunnya, karena program tersebutbanyak menginspirasi masyarakat luas, khususnya generasi muda penghafal $\mathrm{Al}$ Quran. Selain itu agar kontenkonten per segment dibikin sevariatif mungkin dan selalu mencerminkan program bergenre religi yang tidak hanya disukai anak-anak tapi juga disukai masyarakat umum kelas A-B-C.

2. Kerabat Kerja (Team Audition) Hafiz Indonesia untuk melakukan audisi seluruh kotadan pelosok Indonesia, karena banyak pondok pesantren dipelosok daerah yang memiliki santri-santri berbakat. 


\section{DAFTAR PUSTAKA}

\section{Buku}

Salim, Agus. 2006 .Teori dan Paradigma

Penelitian Sosial. Yogyakarta: Tiara

Wacana.

Ahmad, Muda.AK .2006 .Kamus Lengkap

Bahasa Indonesia. Jakarta: Reality

Publisher

Burton,Graeme. 2007. Membicangkan

Televisi. Yogyakarta \& Bandung:

Jalasutra.

F. Andrain,Charles, Kehidupan Politik dan Perubahan Sosial, Yogyakarta:

Tiara Wacana Yogya

H.M.Arifin. Psikologi Dakwah(Jakarta:

Bumi Aksara,1991)

Jalaluddin. 1998. Cetakan ketiga

Psikologi Agama, Jakarta: PT

RajaGrafindo,

J. Moleong, Lexy. 2002. Metodologi

Kualitatif, Bandung PT. Remaja

Rosdakarya,

Kuswandi, Wawan. 1996. Komunikasi

Massa: Sebuah Analisis Isi

MediaTelevisi. Rineka Cipta,

Littlejohn,Stephen W \& Foss, Karen A.

2005, Theories of Human

Communication, $8^{\text {th }}$ edition, USA,

Thomson Wadsworth Chapter9

Loncoln dan Denzim (ed) .1994. Hand

Book of Qualitative Research, Sage

Publication. Thousan oaks, London.

Michael Bland, Alison Theaker, David

Wragg. 2001. Hubungan Media

yang Efektif, Jakarta: Erlangga,

Morissan,. 2005. Media Penyiaran,

strategi mengelola Radio dan

Televisi, Jakarta: RamdinaPrakarsa

Marwah Daud, Dakwah Islam

Tahun2000-an, Makalah Pengantar

pada Stadium General Fakultas

Dakwah IAIN Syaruf

Hidayatullah, 1990

Kriyantono, Rachmat. 2007. Teknik

Praktis Riset Komunikasi: Disertai

Contoh Praktis Riset Media, Public

Relations, Advertising, Komunikasi

Organisasi, Komunikasi
Pemasaran.Jakarta: Kencana

Prenada Media Group.

Sutisno. 1993. P.C.S., Pedoman Praktis

Penulisan Skenario Televisi dan

Radio Jakarta: PT Grasindo,

Sunarjo Djoenaesih S.1983.Himpunan

Istilah Komunikasi, cet ke-2.

Yogyakarta: Liberty

Quail, Denis. 1985.Model-Model

Komunikasi. Alih BahasaPutu

Laxman Pendit. Jakarta: UniPrimas

Wibowo, Fred. 2007. Teknik Produksi

Program Televisi. Yogyakarta: Pinus

Book Publisher.

Sumber Internet

http://rcti.televisi/profile/view/2/Visi

--Misi-Dan-3-Pilar-Utama

diakses Juni 2015RCTI,

http://rcti.televisi/profile/view/1

diakses Juni 2015)

http://pamuncar.blogspot.com/2012/06/d

efinisi-peran-dan-fungsi-

mahasiswa.html

http://pengertianpengertian.blogspot.com /2012/10/pengertian-

kebiasaan.htmll

http://id.wikipedia.org/wiki/Dosen

http://pls.upi.edu/index.php/pls-

profil/sdm/tupoksi-pls

http://www.smkn3tarakan.net/index.php? option=com_content\&view=article \&id= 164:peranan-motivasi-

dalam-belajar\&catid=1:latest-news

\section{Karya Ilmiah}

Makrifatun, "Pengaruh Motivasi Terhadap Peningkatan Hafalan al-Qure an pada Mahasiswa dan Mahasiswi yang Tinggal di Pondok Pesantren Tahfidzul Qur"an al-Asy"eariyyah Wonosobo", Skripsi, Jurusan Pendidikan Agama Islam, Fakultas Tarbiyah, Universitas Islam Negeri Sunan Kalijaga Tahun 2005.

Mufidah, "Motivasi Mahasiswi Menghafal Al-Qurean: Studi kasus 
di Pondok Pesantren Al-Munawwir Krapyak Yogyakarta”, skripsi, Jurusan Pendidikan agama Islam, Fakultas Tarbiyah, Institut Agama Islam Negeri Sunan Kalijaga, Yogyakarta,2003 